\title{
Temporal patterns in the surface abundance of Calanus finmarchicus and C. helgolandicus in the northern North Sea (1958-1996) inferred from Continuous Plankton Recorder data
}

\author{
D. J. Beare ${ }^{1, *}$, E. McKenzie ${ }^{2}$ \\ 'Research Unit for Wildlife Population Assessment, Mathematical Institute, University of St. Andrews, St. Andrews \\ KY16 9SS, Scotland, UK \\ ${ }^{2}$ Department of Statistics and Modelling Science, University of Strathclyde, Glasgow G1 1XH, Scotland, UK
}

\begin{abstract}
Patterns in the temporal abundance of Calanus finmarchicus and C. helgolandicus in 3 sub-regions of the northern North Sea are described from Continuous Plankton Recorder data, updating earlier studies with information from 3 more years (1994, 1995 and 1996). Abundances are considered using time-series techniques that allow the annual seasonal cycles observed within each sub-region to change over the long term. It is demonstrated that, as long-term trends of C. finmarchicus and C. helgolandicus fluctuated in the northern North Sea between 1958 and 1996, simultaneous changes also occurred in the annual seasonal cycles of both species. The results are discussed in relation to local sea-surface temperatures and the North Atlantic Oscillation index.
\end{abstract}

KEY WORDS: Calanus Long-term trends Seasonal patterns North Atlantic Oscillation Sea-surface temperature

\section{INTRODUCTION}

The Continuous Plankton Recorder (CPR) survey, from which the zooplankton data used in the current study are derived, is ongoing, and to preserve its usefulness to the marine-scientific community, analyses of the data collected must be updated regularly since each year brings more information requiring assimilation into existing models and hypotheses. It is also the authors' view that the value of CPR data is not fully appreciated by the marine-scientific community. One reason is that the statistical techniques used to summarise the data (viz. coarse aggregation in time and space) often obscure many of the interesting biological patterns contained within them. The first aim of this paper, therefore, is to produce a simple, graphical summary reference to the long-term, seasonal, and to a limited extent spatial, surface abundances $(7 \mathrm{~m})$ of

·E-mail: douglas@dcs.st-and.ac.uk
Calanus finmarchicus and C. helgolandicus, in the northern North Sea between 1958 and 1996, which also updates previous work on the 2 species (e.g. Fromentin \& Planque 1996, Planque \& Fromentin 1996 , Beare et al. 1998, Planque \& Reid 1998, Beare \& McKenzie 1999a,b). The second aim is to stress the inextricable link between seasonal and long-term patterns in marine biota (Moore 1983, Evans \& Edwards 1993, Frid et al. 1996) and to discuss the implications when attempting to link the patterns to possible predictive variables (e.g. North Atlantic Oscillation index, sea-surface temperature).

\section{MATERIALS AND METHODS}

CPR data for the abundance of Stages 5 and 6 Calanus finmarchicus and C. helgolandicus were obtained from the Sir Alister Hardy Foundation for Ocean Science. Details of the data-collection methods and 
recording protocols of the CPR Survey are well known and have been covered in detail by many authors, e.g. Colebrook (1960), Warner \& Hays (1994), Hays et al. (1993), so that there is no need to revisit them in detail here.

Temporal patterns of abundance were here investigated with Generalized Additive Models (GAMs) (Hastie \& Tibshirani 1993) with a multinomial logit response (McCullagh \& Nelder 1983, Beare \& McKenzie 1999a). GAMs are sophisticated multiple regression models which, because of their flexibility and ready availability, are increasingly finding useful application in marine ecology (e.g. Augustin et al. 1998). Here, GAMs were applied to the CPR data by dividing the data into 3 arbitrary spatial compartments (Fig. 1) and modelling the resulting time-dependence as (smooth) functions (Cleveland 1979) of long-term trend and seasonality.

The models. The models used are described in detail by Beare \& McKenzie (1999a). In brief, the probability of recording 1 of the 13 possible recorded values $(R)$ (see Warner \& Hays 1994) in either of the 3 subregions (Fig. 1) at time $(t, s)$ is modelled as a smooth function of long-term trend $(t)$ or seasonality (s), that is to say we model $\mathrm{p}\left(R_{t s}>\mathrm{r}\right)=\mathrm{p}_{t s r}$, using a logit transformation. Two models were fitted to each data set to test whether the shape of the seasonal cycle changed over the long term (see Beare et al. 1998). The models have the form:

$$
\begin{aligned}
& \ln \frac{\mathrm{p}_{t s t}}{1-\mathrm{p}_{t s r}}=\Pi_{r}+\operatorname{smooth}(t)+\operatorname{smooth}(s) \\
& \ln \frac{\mathrm{p}_{t s t}}{1-\mathrm{p}_{t s t}}=\Pi_{r}+\operatorname{smooth}(t, s)
\end{aligned}
$$

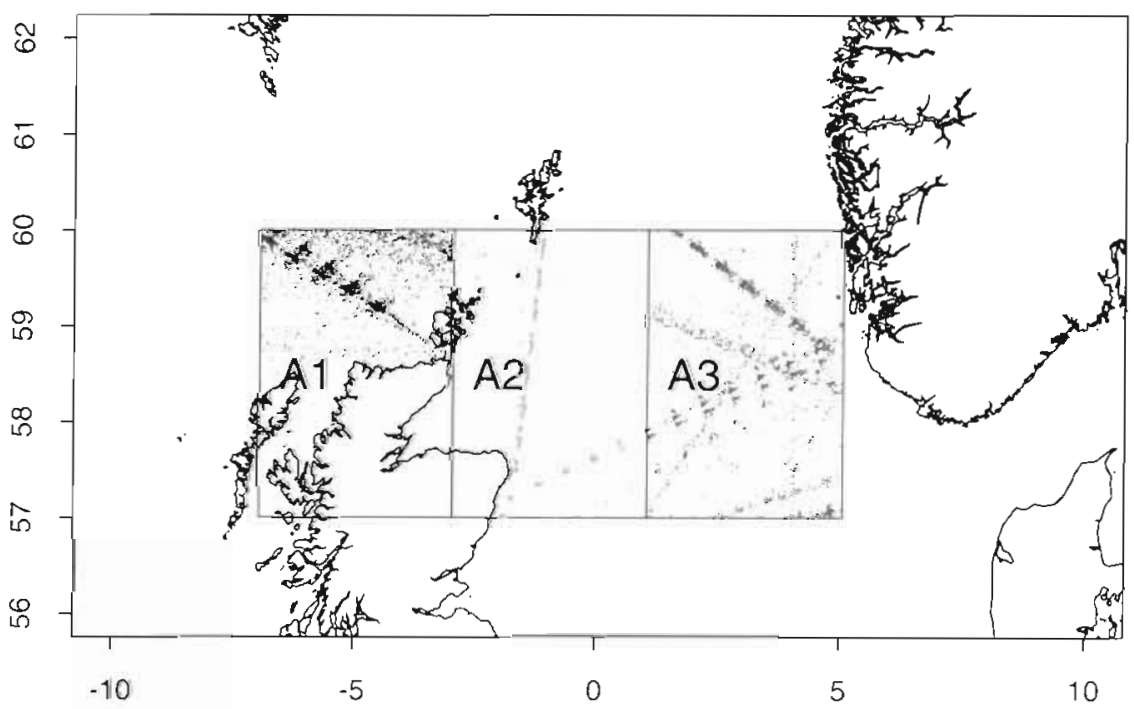

Fig. 1. Location of Areas 1, 2, and 3 and distribution of CPR observations where $\Pi_{r}$ is a factor corresponding to the observed recorded value, $r$. The second and third factors on the right in Model 1 display the dependence of the logit of $\mathrm{p}_{t s I}$ on smooth functions (locally weighted regression, see Cleveland \& Devlin 1988) of long-term trend and seasonality separately. Model 1 is the traditional 'longterm trend plus seasonality' model where dependence of the distribution of recorded values on the seasonal cycle is assumed to remain unchanged throughout the 39 yr of observation. Conversely, in Model 2 the variables of long-term trend and seasonality are allowed to covary together which, in practical terms, allows dependence on a changing seasonal cycle to be modelled if appropriate.

GAMs were used because they allow 2-dimensional dependency to be assayed without the imposition of any rigid functional form. The multinomial logit response was adopted within the GAM fits because it eliminates statistical problems relating to the recording protocol by treating the 13 recorded values as ordinal response variables rather than as numbers directly, see Beare \& McKenzie (1999a) for further details.

\section{RESULTS}

\section{Long-term changes}

\section{Calanus finmarchicus}

In the westernmost Area (Area 1), to the north of Scotland, (Fig. 1) mean Calanus finmarchicus abundance ranged between 0.5 and 34.2 ind. per $3 \mathrm{~m}^{3}$ rising from relatively low levels in the late 1950 s to a peak in June 1963 after which abundances fell gradually during the 


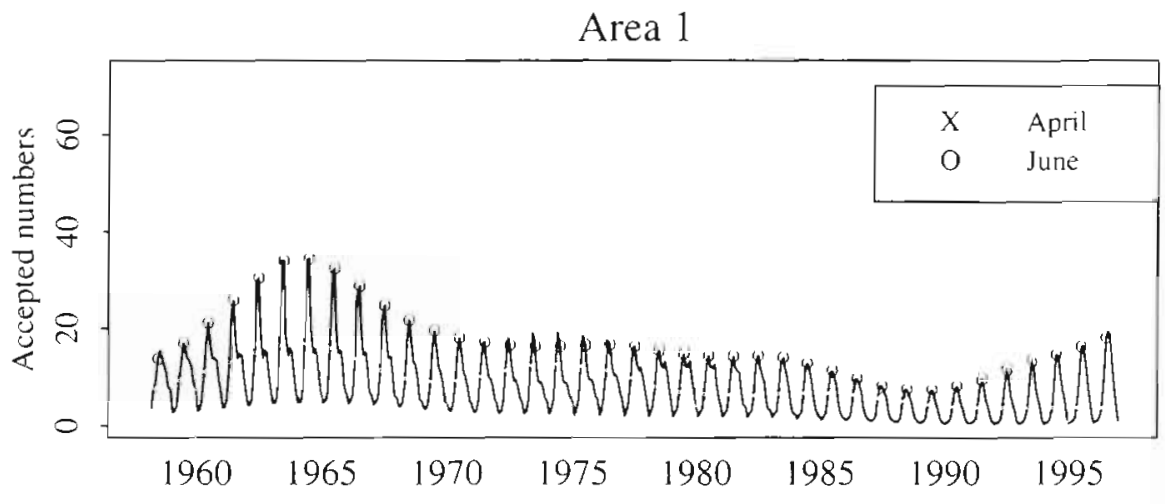

Area 2

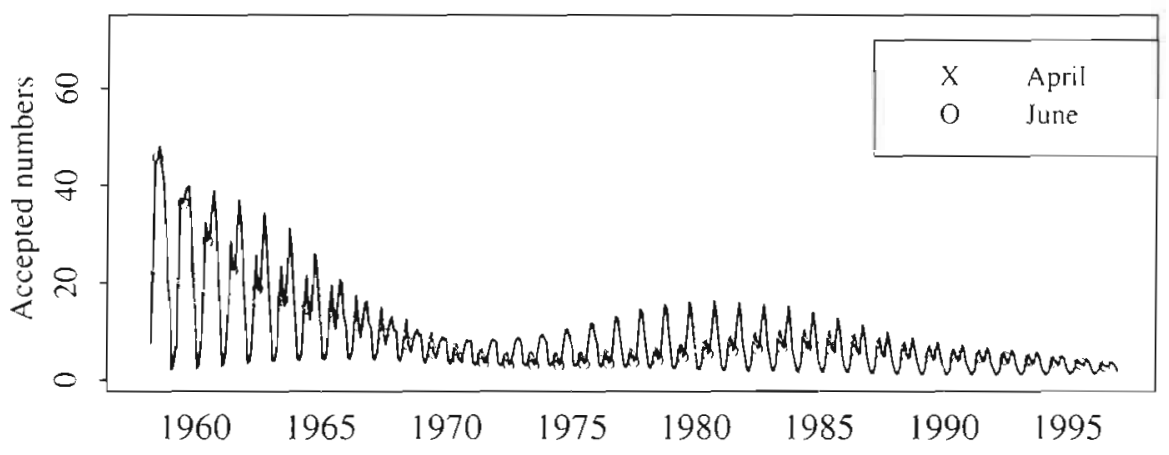

Area 3

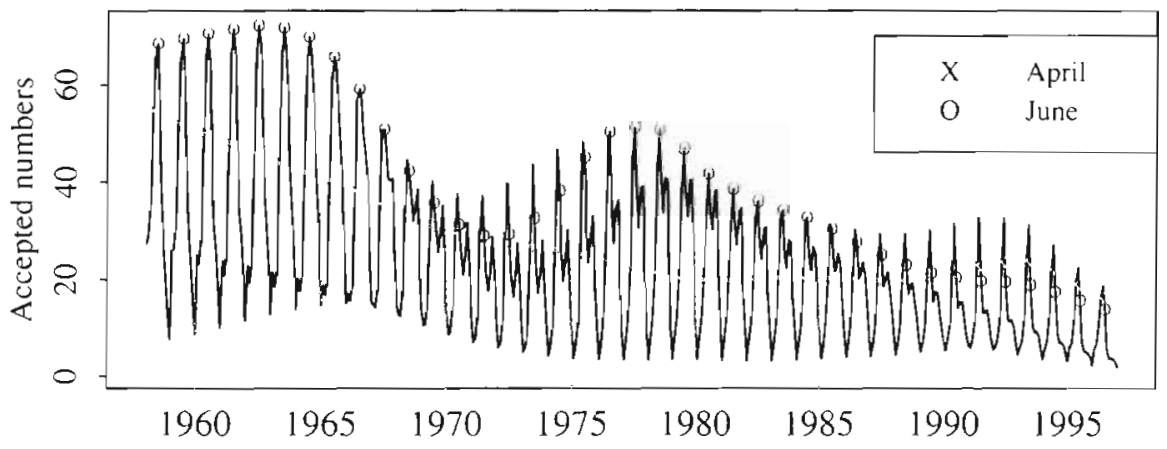

Fig. 2. Long-term abundance (ind. per $3 \mathrm{~m}^{3}$ ) of Calanus finmarchicus in Areas 1 to 3 between 1958 and 1996 estimated using Model 2. Unstable seasonality in the data is emphasised by highlighting the months of April and June

1970 s and 1980s (Fig. 2). The lowest densities were recorded in 1989 since which time there has been a small increase focused on June (Fig. 2). Long-term trend also fell in Areas 2 and 3 overall (Fig. 2), and there was a particularly sudden collapse in the late 1960s, followed by a partial recovery centred on 1981 (Area 2) and 1977 (Area 3) since which time numbers have fallen again. To put this decrease into perspective, numbers in the mid1990 s in Area 2 are about one-fifth of what they were in the late 1950 s and early 1960 s (see also Beare et al. 1998).

\section{Calanus helgolandicus}

Surface $(7 \mathrm{~m})$ abundances of Stages 5 and 6 Calanus helgolandicus in Area 1 are about one-third of those recorded for $C$. finmarchicus and vary between 0.2 and 11.2 (Fig. 3). Long-term trend in abundance fell between 1958 and 1976 and rose again thereafter (Fig. 3). In Area 2, surface abundances of C. helgoIandicus were very similar (0.2 to 12.51 ind. per $\left.3 \mathrm{~m}^{3}\right)$ to those observed in Area 1, although the form of the 

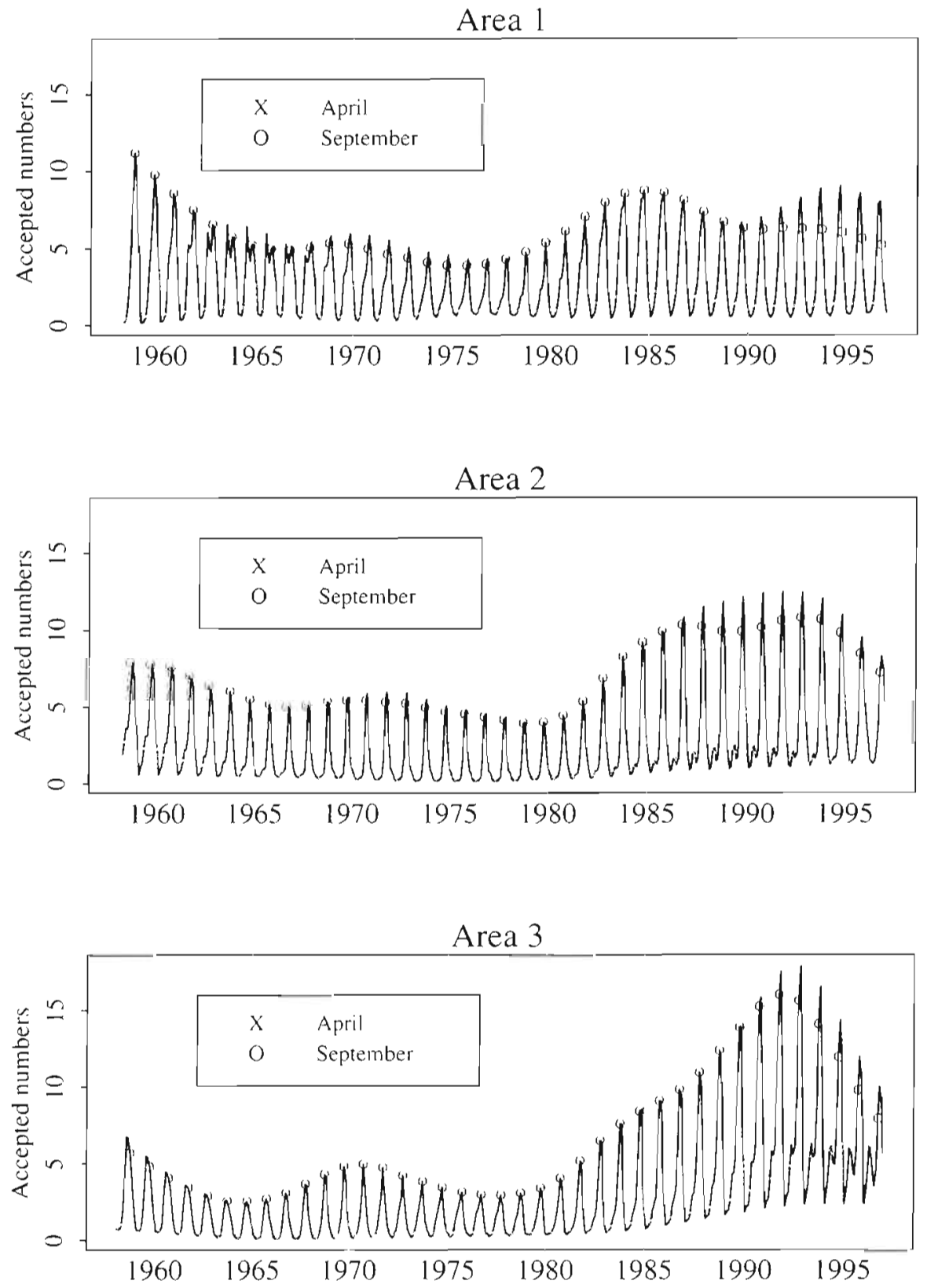

Fig. 3. Long-term abundance (ind. per $3 \mathrm{~m}^{3}$ ) of Calanus helgolandicus in Areas 1 to 3 between 1958 and 1996 estimated using Model 2. Unstable seasonality in the data is emphasised by highlighting the months of April and September

long-term trend is different (Fig. 3). In this area there was a similar but shallower decline between 1958 and 1965, after which there was little change until ca 1980 when abundances began to increase, peaking in 1992 since which time they have fallen again (Fig. 3). There were also recent increases in the abundance of $\mathrm{C}$. helgolandicus in Area 3 between 1980 and 1992 and the range of abundance (0 to $17.90 \mathrm{ind}$. per $3 \mathrm{~m}^{3}$ ) measured was higher than that seen for the species further to the west in Areas 1 and 2 (Fig. 3).

\section{Changes in seasonal pattern}

\section{Calanus finmarchicus}

In Area 1, the seasonal cycle was generally unimodal each year, with main peaks in either May or June, although in a few years (1960 to 1967) a smaller September peak was seen (Fig. 2). In the adjacent subarea to the east (Area 2), the time-series for mean Calanus finmarchicus abundance was completely dif- 


\section{Area 2}
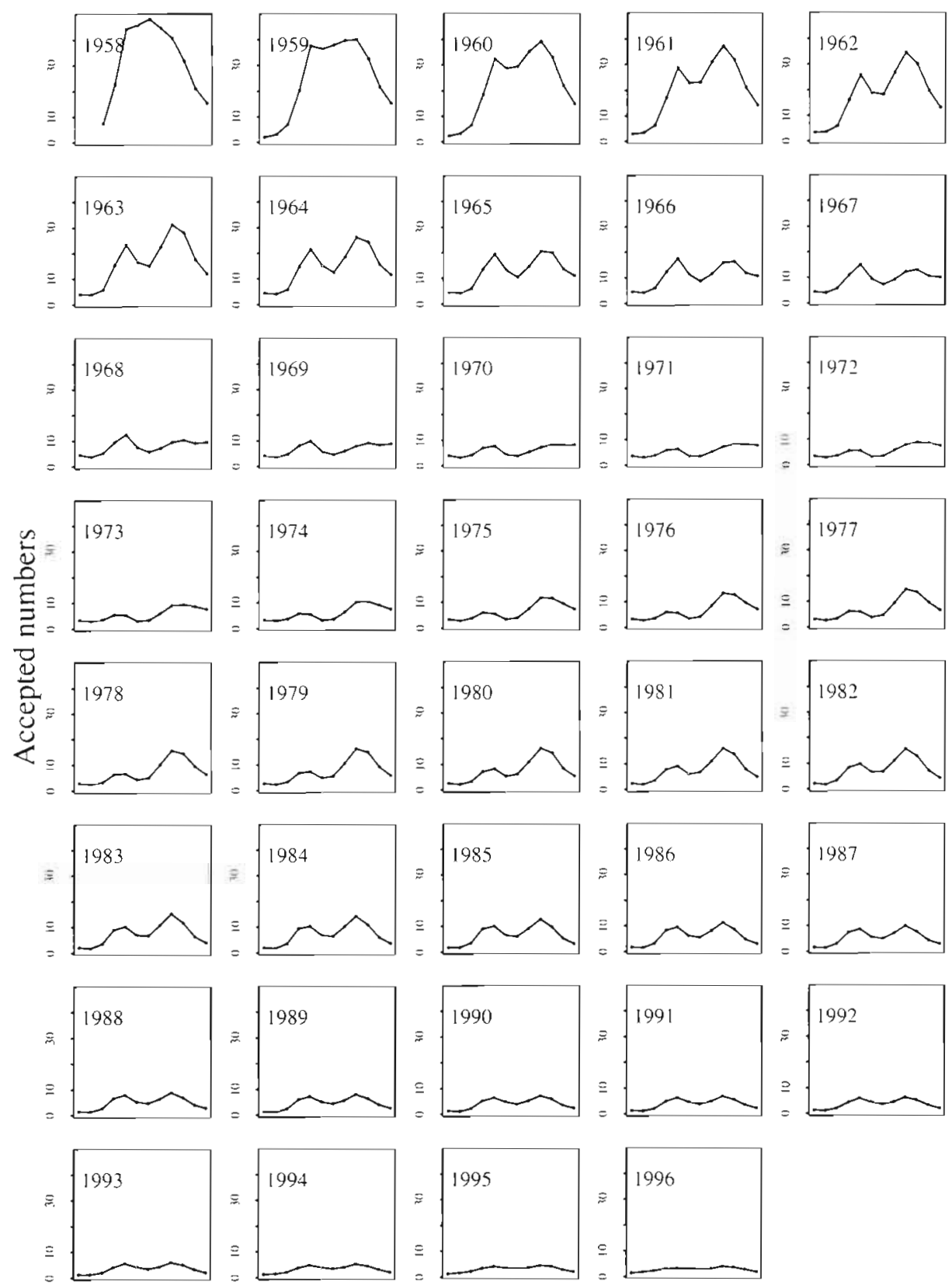

Fig. 4. Annual cycles of abundance (ind. per $3 \mathrm{~m}^{3}$ ) between 1958 and 1996 of Calanus finmarchicus in Area 2. June is indicated by dotted vertical line (NB: data are the same as those plotted in Fig. 2 [top])

ferent, being bimodal in all years except 1958 and 1959 (Figs. 1, 2 \& 4). The first peak occurred in either April or May; June was always a midsummer minima, and the second peak occurred in August or September each year (Fig. 4). In Area 3, in relatively deeper water, close to the west coast of Norway, mean abundances of C. finmarchicus were slightly higher than those seen more to the west in Areas 1 and 2 (Fig. 5) and the seasonal dynamic in the area was extremely complex
(Figs. 2 \& 5) with unimodal cycles recorded for 1 decade (from 1958 to 1968) after which cycles became bimodal. Interestingly, the bimodal seasonality in Area 3 was completely unlike that observed to the west in Area 2 (see Fig. 4). In Area 2 the second (late-summer) peak in the year is larger than the first one in the majority of years studied (NB not from 1966 to 1970), while in Area 3 the first of the 2 peaks each year, in either May or June, is always larger than the second 


\section{Area 3}
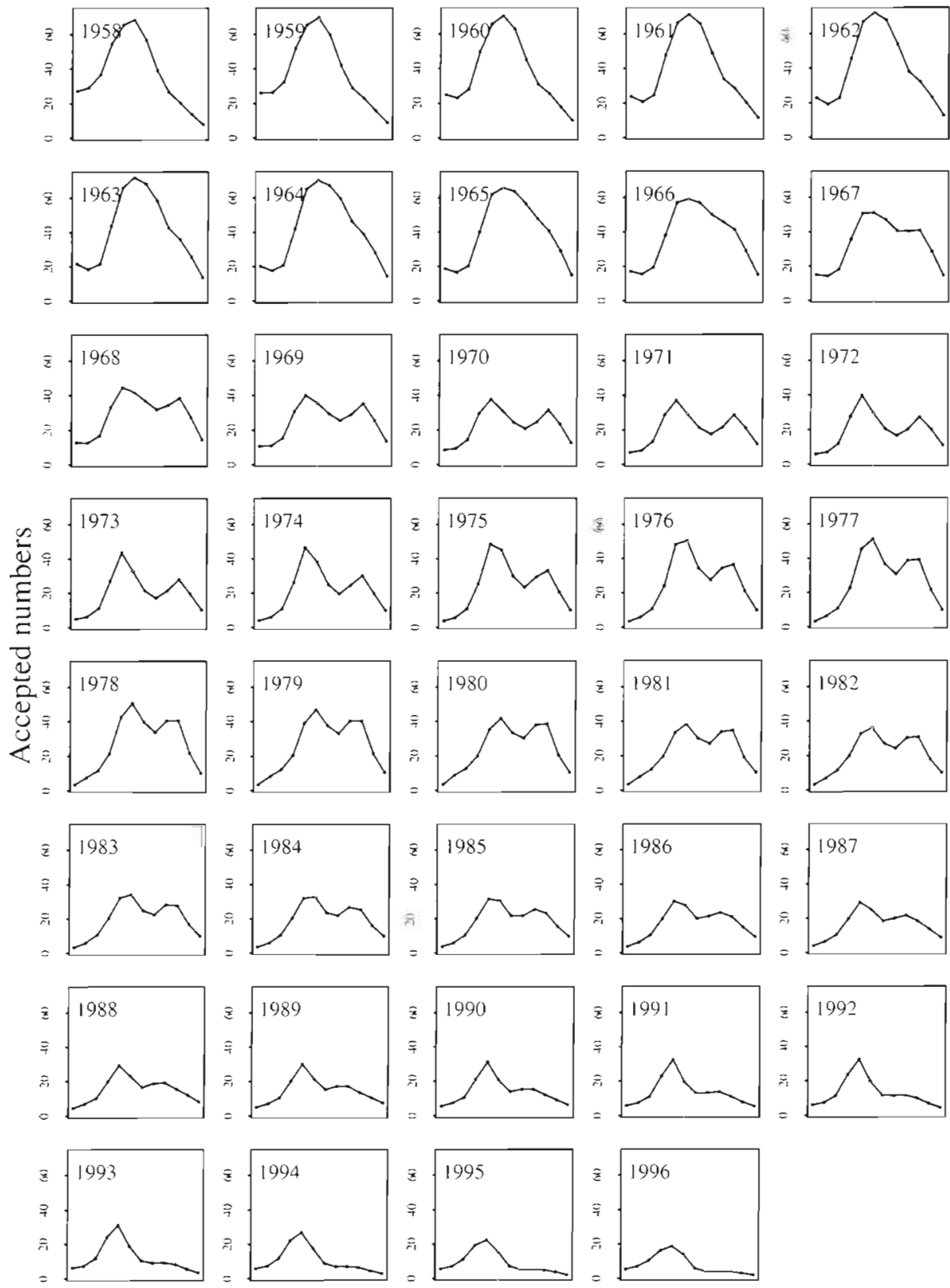

Fig. 5. Annual cycles of abundance (ind $3 \mathrm{~m}^{-3}$ ) between 1958 and 1996 of Calanus finmarchicus in Area 3. June is indicated by dotted vertical line (NB: data are the same as those plotted in Fig. 2 [bottom])

(Figs. $2 \& 5$ ). In addition, generally the mid-year minima in Area 3 occur later in the year than those in Area 2 (Figs. 4 \& 5).

\section{Calanus helgolandicus}

The seasonal cycles of Calanus helgolandicus abundance changes were also strongly time-dependent
(Fig. 6). Annual cycles were unimodal between 1958 and 1960, bimodal between 1961 and ca 1968, after which they were generally unimodal. The timing of the (usually largest) late-summer, autumn peak also varied inter-annually, and was recorded in August (1989 to 1996), September (1958 to $1962 ; 1977$ to 1988) and October (1967 to 1976). Between 1963 and 1966, when the seasonal cycle was bimodal, the larger peak in the year occurred in mid-summer, in June (Fig 6). 


\section{Area 1}
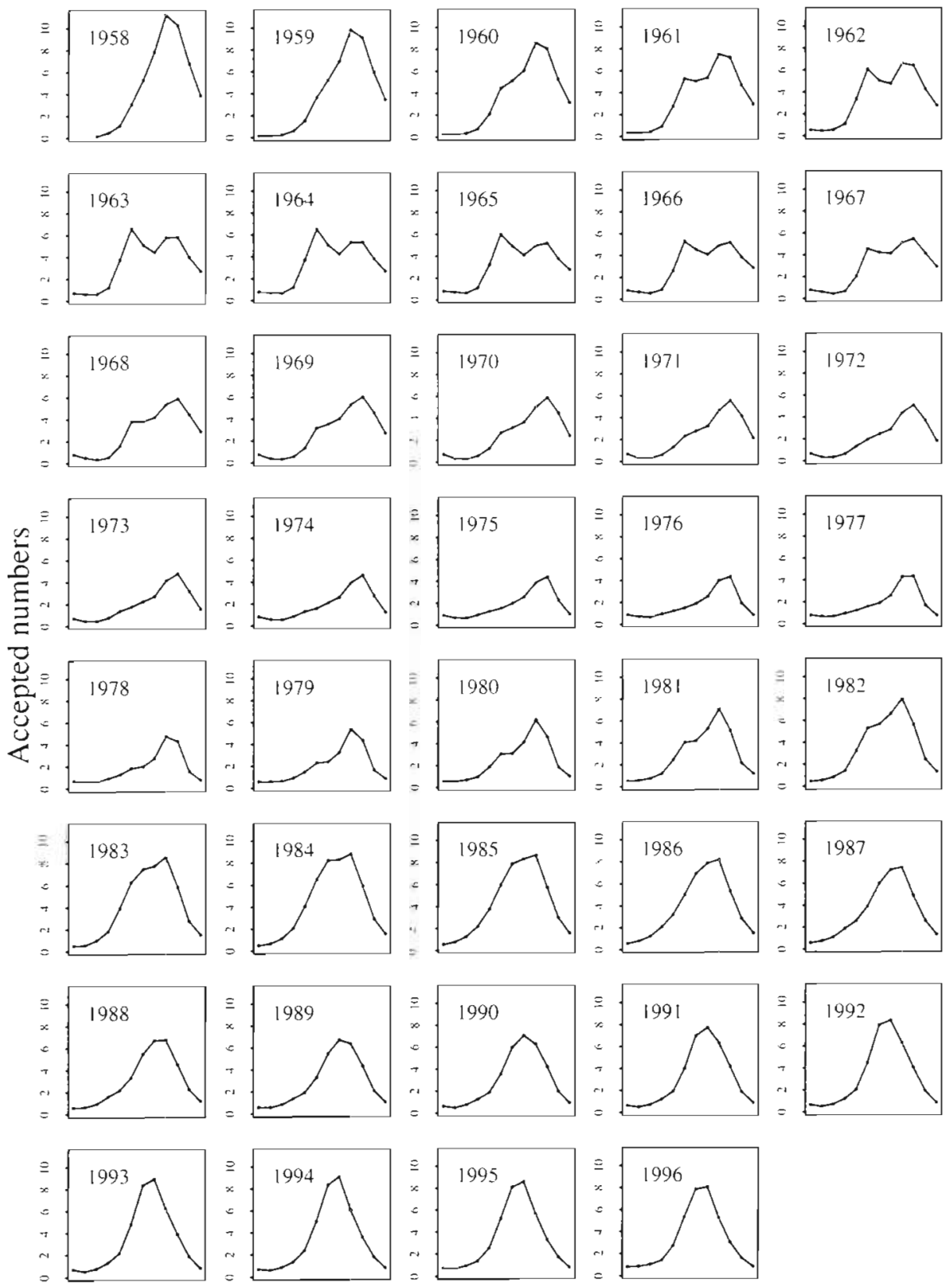

Fig. 6. Annual cycles of abundance (ind per $3 \mathrm{~m}^{3}$ ) between 1958 and 1996 of Calanus helgolandicus in Area 1. September is indicated by dotted vertical line (NB: data are the same as those plotted in Fig. 3 [top])

The form of the seasonal cycle of Calanus helgolandicus in Area 2 was generally more stable than reported for Area 1, and autumn peaks were centred on September and October (Fig. 3). During the period of most dramatic surface population increases (1980 to 1992), a small spring peak appeared in April/May which disappeared again between 1994 and 1996 when long-term trend was once again falling.
The annual cycles were mostly unimodal in Area 3 (Fig. 7), with the main peak occurring in the late summer. Particularly early-July peaks were seen between 1958 and 1960, after which the more typical pattern of annual September maxima took over until ca 1990, when October peaks were observed. When the abundance of Calanus helgolandicus was rising in Area 3 between 1980 and 1992 an April/May peak 


\section{Area 3}
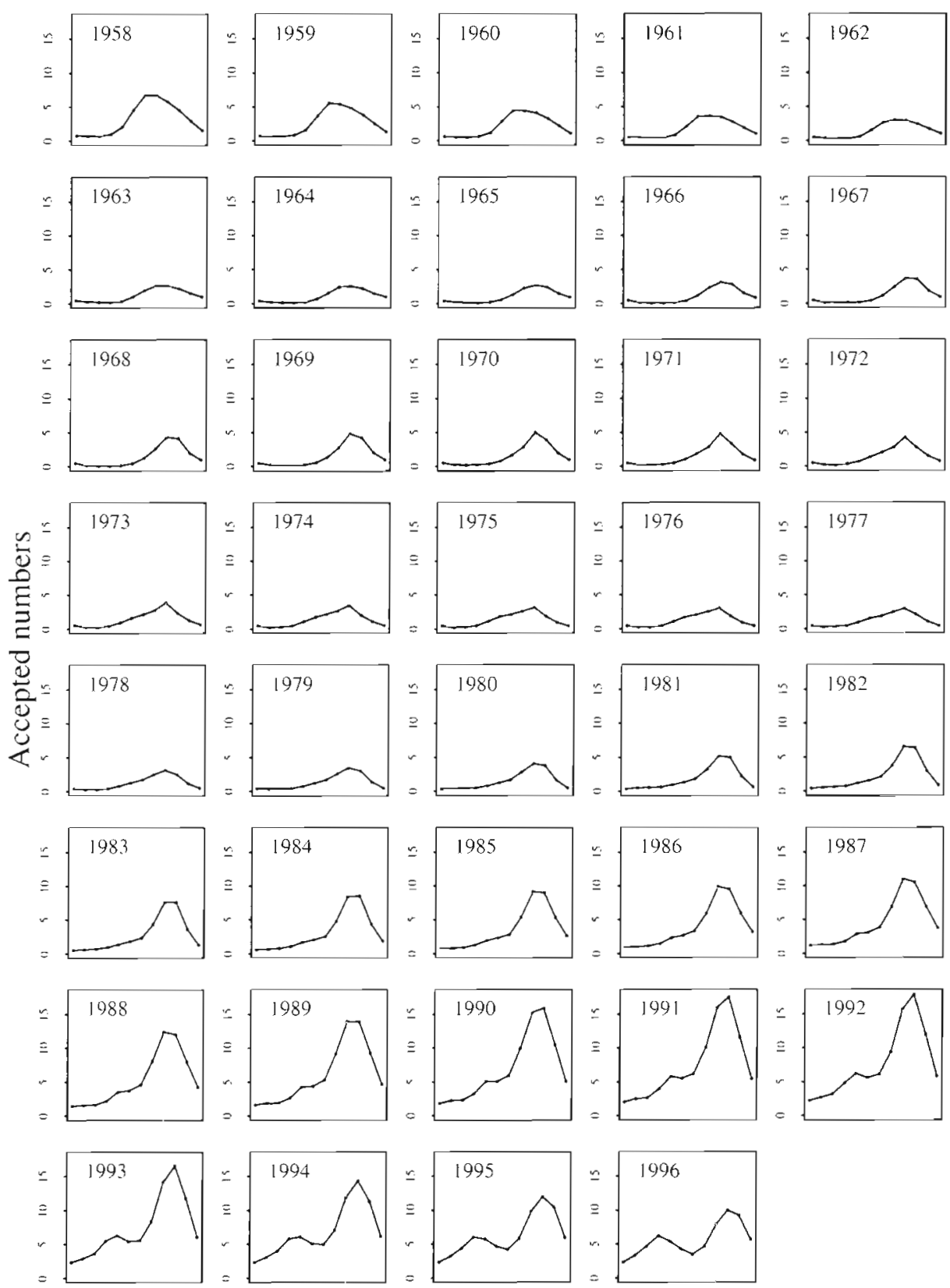

Fig. 7. Annual cycles of abundance (ind. per $3 \mathrm{~m}^{3}$ ) between 1958 and 1996 of Calanus helgolandicus in Area 3. September is indicated by dotted vertical line (NB: data are the same as those plotted in Fig. 3 [bottom])

emerged as noted in Area 2, although unlike Area 2 it has persisted into 1996 (Figs. 6 \& 7 ).

\section{DISCUSSION}

This study involves adult (Stages 5 and 6) Calanus finmarchicus and $C$. helgolandicus only, collected at a depth of ca $10 \mathrm{~m}$, and the patterns of abundances described therefore may not adequately reflect the actual population density. Specifically, the numbers of preceding naupliar and copepodite stages are likely to be poorly described, as are adult densities throughout the water column. The CPR data, however, are the only source of information available at these large temporal and spatial scales, and there is no alternative but to analyse them, examine them and ultimately interpret the results carefully. 
It is well known (1958 to 1993) that the abundance of (adult) Calanus finmarchicus has generally collapsed in the northern North Sea since the 1960s, while that of (adult) C. helgolandicus has risen, although these new data suggest that the rising trend in C. helgolandicus abundance has not persisted into 1994, 1995 and 1996 (Figs. 2 \& 3). The negative, linear overall long-term correlations between $C$. finmarchicus and $C$. helgolandicus reported by Planque \& Fromentin. (1996) are superficial, and the long-term interaction between the 2 animals is more complex (Figs. $2 \& 3$ ).

Fromentin \& Planque (1996) suggested that the decline of Calanus finmarchicus in the northern North Sea was related to the North Atlantic Oscillation (NAO) index, possibly mediated through its influence on primary productivity (Fromentin \& Planque 1996. Planque \& Fromentin 1996). The relationship, however, has now broken down because the recent strong negative NAO indices (Beare \& McKenzie 1999c) should have caused a rise in the abundance of $C$. finmarchicus in the northern North Sea, which has not happened (see also Planque \& Reid 1998).

In very general terms, the NAO index is capable of providing a good overall synopsis of the hydro-meteorology of the North Atlantic (Hurrel 1996) The winter part of the NAO time-series is usually the only part considered and is related most strongly to winter meteorology (Jones et al. 1997). In addition it has a strongly regional influence (Becker \& Pauly 1997). During the 1960 s, winter NAO was in a negative phase, leading to the synoptic pattern of cold winters in Europe and warm ones on the other side of the Atlantic (Hurrel \& VanLoon 1996). Since the 1960 s, the long-term trend in the winter part of the NAO has risen steadily, and the 1990s were characterized by positive NAO indices leading to an increase in overall European winter-time temperatures, precipitation and south-westerly wind stress.

The NAO index, however, is not necessarily a useful summary of meteorology at every location across the North Atlantic and within the North Sea (Becker \& Pauly 1996). In Fig. 8, raw sea-surface temperature data for the period 1950 to 1992 in Areas 1 to 3, using the Comprehensive Ocean Atmosphere Dataset, are plotted against absolute time. Long-term (solid line), April and September trends in these data are emphasised using variable-span smoothing functions (see Fig. 8). In Areas 1 and 2, sea-surface temperatures in all seasons were higher between the late-1950s and mid-1960s than they were between 1975 and 1985 (Fig. 8). Between 1985 and 1992, sea-surface temperatures rose again in Areas 1 and 2, although the levels of the 1950s and 1960s have not been re-attained (see Fig. 8).

In Area 3, winter temperatures (e.g. April) were lower in the 1950s and 1960s than they were in the 1980s and 1990s, while summer temperatures (e.g September) demonstrated the reverse trend with higher levels in the 1950s and 1960s (Fig. 8). According to the literature, the east versus west regional signature of the NAO should be most pronounced in Area 3 (Hurrel 1995, 1996, Hurrel \& VanLoon 1997) and winter sea-surface temperatures were indeed lower in the 1950 s and 1960 s, with many more deep winter minima recorded in those 2 decades than have been observed since 1970 (see Fig. 8). We believe that this specific signal (rising winter temperatures) is related to the negative NAO index of the 1960 s and positive NAO index of the 1990s and fits the accepted (Hurrel \& VanLoon 1997) pattern of NAO influence across the North Atlantic.

Note, however, that summer-time sea-surface temperatures were actually warmer in the $1960 \mathrm{~s}$ in Areas 1,2 , and 3. In Area 3 the warmer summers were preceded by a series of exceptionally cold winters (Fig. 8), and thus cold winters are not necessarily followed by cold springs, summers and autumns, providing yet more evidence underlining the need to examine changing seasonality in environmental time-series extremely carefully (Beare \& McKenzie 1999a,b,c) before drawing conclusions.

The winter NAO index may then be a poor direct predictor of spring, summer, autumn and sometimes even winter sea-surface temperatures in the northern North Sea, and for this reason may also be inadequate for explaining changes in its biota which grow and reproduce mainly between March and October. There is also no clear suggestion from these data (Figs. 2, 3 $\& 8$ ) that sea-surface temperature changes are directly related to the long-term trends and seasonal patterns that we have observed in surface Stages 5 and 6 Calanus finmarchicus and $C$. helgolandicus abundances either. Numbers of both Calanus species fell in the 1960s (Figs. $2 \& 3$ ), and they both reached minima in the late 1970 s when sea-surface temperatures were also low (Fig. 8). 1979 was the coldest year of all between 1950 and 1992 (Fig. 8, see also Becker \& Pauly 1997).

Calanus helgolandicus is a Mediterranean species (Williams 1985, Bryant et al. 1997) which, here at the northern limit of its distribution, grows faster in higher water temperatures (Jaschnov 1970), viz. the late summer peak and appearance of a spring peak as temperatures rose (Figs. $6 \&$ 7). Since 1980 its abundance has increased in the northern North Sea, but the increase clearly began before the sea-surface temperatures rose, implying no direct causal link (Fig. 8). Also, warmer sea-surface temperatures should then have precipitated a rise in the abundance of $C$. finmarchicus since 1985 if it was the direct cause of its demise in the late 1960s (Fig. 3). 

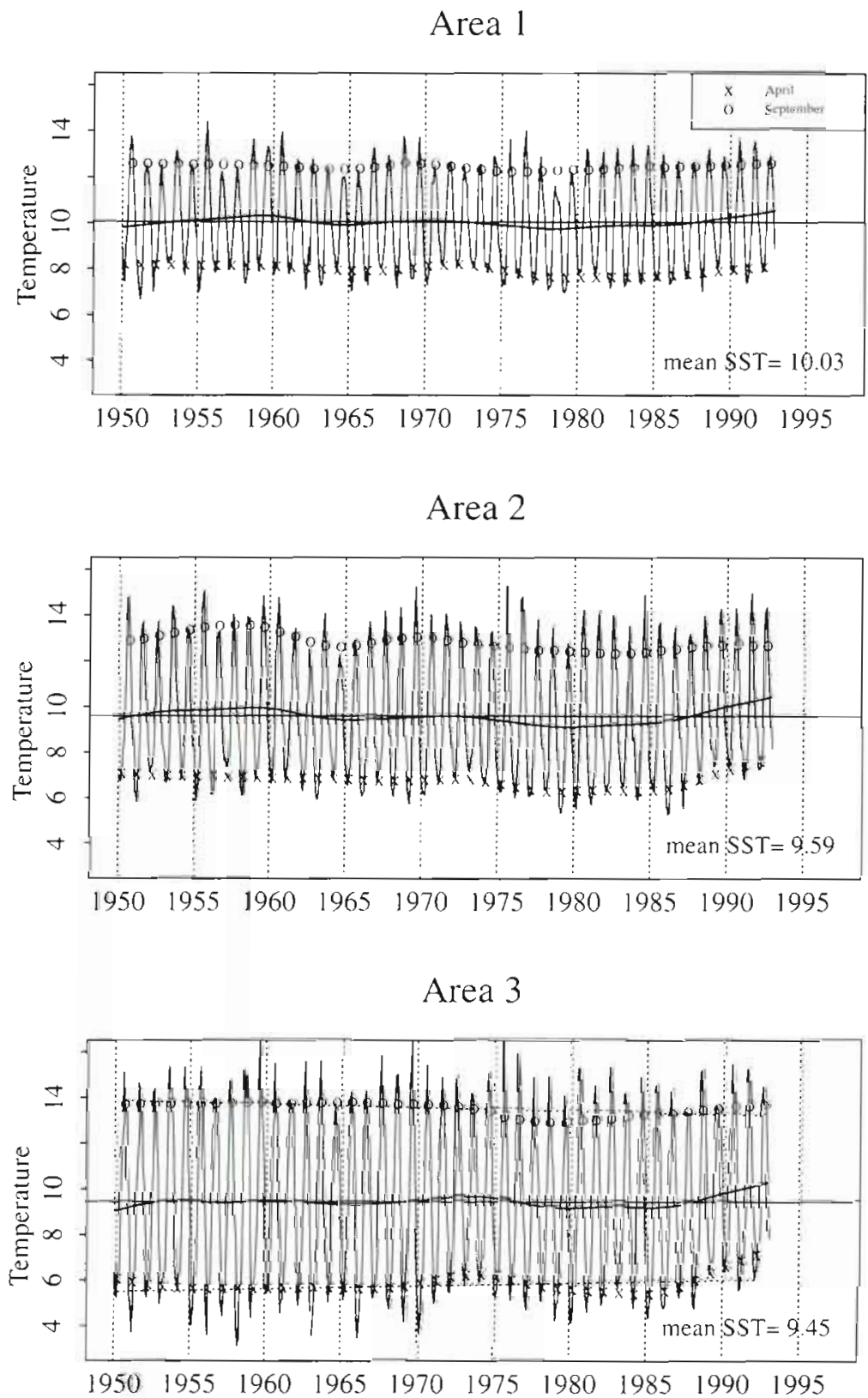

Fig. 8. Long-term trends in sea-surface temperature in Areas 1 to 3. Long-term trends in April (o) and September (x) ate summarised by the application of a variable-span smoothing filter to the raw data for that month. In Area 3, April and September trends are further emphasised with a linear model (dotted lines)

One explanation for the temporal patterns seen in the 2 Calanus species is that Atlantic influence and inflow (Corten 1990, Stephens et al. 1998) into the North Sea were greater in the 1960 s and more Calanus were imported: C. finmarchicus from overwintering locations beyond the continental shelf and $C$. helgolandicus from the north and west of Scotiand via the Fair Isle Current (Backhaus et al. 1994, Heath et al. 1999). The waning of relatively warm Atlantic inflow left a signature of falling temperatures (see Fig. 8, e.g
Stefansson \& Olafsson 1991, Gislason \& Asthorsson 1996, Asthorsson \& Gislason 1998, Reid et al. 1998, Stephens et al. 1998). In the absence of strong competition from $C$. finmarchicus, the numbers of $C$. helgolandicus (Fromentin \& Planque 1996, Planque \& Fromentin 1996, Planque \& Reid 1998) began to increase, aided latterly by higher sea-surface temperatures (Fig. 8).

This explanation, however, is also unsatisfactory. If the recent high sea-surface temperatures (1988 to 
1992) were caused by an increase in Atlantic inflow to the northern North Sea (Heath et al. 1991, Stephens et al. 1998) why were more Calanus finmarchicus not imported from offshore overwintering locations? Our failure to adequately explain the long-term trends in the surface abundances of C. finmarchicus and C. helgolandicus is probably attributable to the lack of information at similar temporal (long-term and seasonal) scales for other potentially important factors, e.g. stratification indices, Atlantic inflow and biological variables, and we hope that this contribution may stimulate further research in that specific direction.

Acknowledgements. Thanks go to all members of the Sir Alister Foundation for Ocean Science for collecting and supplying the data, to 3 anonymous referees who improved an earlier version of this manuscript, and to the European Union for funding the TASC (Trans-Atlantic Study of Calanus finmarchicus) Project, contract number MAS3-CT95-0035, and the ICOS (Investigation of Calanus finmarchicus migrations between oceanic and shelf seas of north-west Europe) Project.

\section{LITERATURE CITED}

Astthorsson OS, Gislason A (1998) Environmental conditions, zooplankton and capelin in the waters north of Iceland. ICES J Mar Sci 55:808-810

Augustin NH, Borchers DL, Clarke ED, Buckland ST, Walsh $M$ (1998) Spatio-temporal modelling for the annual egg production method of stock assessment using generalized additive models. Can J Fish Aquat Sci 55:2608-2621

Backhaus JO, Harms IH, Krause M, Heath MR (1994) An hypothesis concerning the space-time succession of Calanus finmarchicus in the northern North Sea. ICES J Mar Sci 51:169-180

Beare DJ, McKenzie E (1999a) The multinomial logit model: a new tool for exploring Continuous Plankton Recorder data. Fish Oceanogr 8(Suppl 1):25-39

Beare DJ, McKenzie E (1999b) Continuous Plankton Recorder data and diel vertical migration in stage $\mathrm{V}$ and VI Calanus finmarchicus: a statistical analysis. Fish Oceanogr 8(Suppl 1):126-137

Beare DJ, McKenzie E (1999c) Connecting ecological and physical time-series: the potential role of changing seasonality. Mar Ecol Prog Ser 178:307-309

Beare DJ, McKenzie E, Speirs DC (1998) The unstable seasonality of Calanus finmarchicus in the Fair Isle Current. J Mar Biol Assoc UK 78:1377-1380

Becker GA, Pauly M (1996) Sea surface temperature changes in the North Sea and their causes. ICES J Mar Sci 53:887-898

Bryant AD, Heath MR, Gurney WSC, Beare DJ, Robertson W (1997) The seasonal dynamics of Calanus finmarchicus: development of a three-dimensional structured population model and application to the northern North Sea. J Sea Res 38:361-379

Cleveland WS (1979) Robust locally-weighted regression and smoothing scatterplots. J Am Stat Soc 74:829-836

Colebrook JM (1960) Continuous plankton pecords: methods of analysis, 1950-1959. Bull Mar Ecol 5:51-64

Corten A (1990) Long-term trends in pelagic fish stocks of the North Sea and adjacent waters and their possible connection to hydrographic changes. Neth J Sea Res 25:227-235

Evans FE, Edwards A (1993) Changes in the zooplankton community off the coast of Northumberland between 1969 and 1988 , with notes on changes in the phytoplankton and benthos. J Exp Mar Biol Ecol 172:11-29

Frid CLJ, Buchanan JB, Garwood PR (1996) Variability and stability in benthos: twenty-two years of monitoring off Northumberland. ICES J Mar Sci 53:978-980

Fromentin JM, Planque B (1996) Calanus and environment in the eastern North Atlantic. II. Influence of the NAO on C. finmarchicus and C. helgolandicus. Mar Ecol Prog Ser 134:111-118

Gislason A, Astthorsson OS (1996) Seasonal development of Calanus finmarchicus along an inshore-offshore gradient southwest of Iceland. Ophelia 44:71-84

Hastie T, Tibshirani R (1990) Generalized additive models. Chapman and Hall, London

Hays GC, Carr MR, Taylor A (1993) The relationship between gulf stream position and copepod abundance derived from the Continuous Plankton Recorder survey: separating biological signal from sampling noise. J Plankton Res 15 : $1359-1373$

Heath MR. Henderson EW, Slesser G, Woodward EMS (1991) High salinity in the North Sea. Nature 352:116

Heath MR, Backhaus JO, Richardson K, McKenzie E, Slagstad D, Beare D, Dunn JD, Fraser JG, Gallego A, Hainbucher DA, Hay SJ, Jónasdóttir S, Madden H, Mardaljevic J, Schacht A (1999) Climate fluctuations and the spring invasion of the North Sea by Calanus finmarchicus. Fish Oceanogr 8(Suppl 1):163-176

Hurrel JW (1996) Influence of variations in extratropical wintertime teleconnections on northern hemisphere temperatures. Geophys Res Lett 23:665-668

Hurrel JW, VanLoon H (1997) Decadal variations in climate associated with the North Atlantic Oscillation. Clim Change 36:301-326

Jaschnov WA (1970) Distribution of Calanus species in the seas of the northern hemisphere. Int Rev Ges Hydrobiol 55:197-212

Jones PD, Jonsson T, Wheeler D (1997) Extension to the North Atlantic Oscillation using early instrumental pressure observations from Gibraltar and south-west Iceland. Int J Climatol 17:1433-1450

McCullagh P. Nelder JA (1983) Generalized Linear Models. Chapman and Hall, London

Moore PG (1983) The apparent role of temperature in breeding initiation and winter population structure in Hyale nilssoni Rathke (Amphipoda): field observations 1972-1983. J Exp Mar Biol Ecol 71:237-248

Planque B, Fromentin JM (1996) Calanus and environment in the eastern North Atlantic. I. Spatial and temporal patterns of Calanus finmarchicus and C. helgolandicus. Mar Ecol Prog Ser 134:101-109

Planque B, Reid PC (1998) Predicting Calanus finmarchicus abundance from climatic signal. J Mar Biol Assoc UK 78 : 1015-1018

Reid PC, Planque B, Edwards M (1998) Is observed variability in the long-term results of the continuous plankton recorder survey a response to climate change? Fish Oceanogr $7: 282-288$

Stefansson U, Olafsson $J$ (1991) Nutrients and fertility of Icelandic waters. Rit Fiskideildar 12(3):1-56

Stephens JA, Jordan MB, Taylor AH, Proctor R (1998) The effects of fluctuations in North Sea flows on zooplankton abundance. J Plankton Res 20:943-956

Warner AJ, Hays GC (1994) Sampling by the continuous plankton recorder survey. Prog Oceanogr 34:237-256

Williams R (1985) Vertical distributions of Calanus finmarchicus and C. helgolandicus (Crustacea: Copepoda). Mar Biol $60: 47-56$

Submitted: March 3, 1999; Accepted: June 18, 1999

Proofs received from author(s): November 24, 1999 